\title{
O consumo de moda durante a pandemia da Covid-19: os discursos no perfil @voguebrasil
}

Fabrícia Karla de Oliveira Santos Pereira, Anna Karollina Oliveira Silva e Lívia Fernanda Nery da Silva

\section{INTRODUÇÃO}

O presente artigo tem como objetivo analisar postagens publicadas no ano de 2020 pelo perfil @voguebrasil, ano referente ao início da pandemia Covid-19 no Brasil, com o objetivo de identificar como a moda utilizou estrategicamente dos discursos sobre a pandemia de Covid-19 para incitar o consumo de produtos de moda.

Centrando-se na problemática da moda em meio a pandemia da Covid-19, a rápida disseminação causada pelo coronavírus gerou impactos e mudanças consideráveis relacionados à indústria da moda. Em março de 2020, a Organização Mundial da Saúde (OMS) 
declarou estado de calamidade pública em decorrência da pandemia Covid-19, com isso foram aplicadas as medidas de restrições sanitárias, a fim de evitar a disseminação do novo vírus.

Devido às medidas de isolamento, o comércio físico sofreu modificações e restrições para continuar com suas atividades. A pandemia impactou no comportamento dos consumidores que preferiram as compras online no comércio varejista. E nessa corrida pela digitalização e inovação no mundo da moda, o Brasil não ficou para trás, pois o e-commerce cresceu $69 \%$ em 2020 , como revelou levantamento do índice e indicadores do mercado online - MCC-ENET ${ }^{1}$. Além disso, o setor de vestuário foi o que registrou a maior expansão, com 125\% em comparação com abril de 2020 (ESQUIVEL, 2021).

Com o início da pandemia da Covid-19 no Brasil e o decreto de isolamento social como medida para conter a disseminação do vírus, as redes sociais se tornaram as principais formas de socialização. Ligeiramente no Instagram, fotos tiradas em casa com hastags \#quarenta, \#isolamentosocial, \#ficaemcasa, dominam os feeds e os stories das redes sociais. As pessoas isoladas publicaram com mais frequência nas redes as suas rotinas durante o período pandêmico. No mês de março de 2020, o uso geral dos aplicativos como Instagram, Facebook e Whatsapp tiveram um crescimento de cerca de $40 \%$, destacando-se a ferramenta lives, do Instagram, que cresceu $70 \%$ no mesmo mês, de acordo com um estudo realizado pela Spark (PORTAL DA COMUNICAÇÃO, 2020). Mostrando assim, que a intimidade individual espetacularizada passou a ser ainda mais exposta,

1 É o resultado de uma parceria formada entre o Compre \& Confie e a camara-e.net. O MCC-ENET é o primeiro indicador a fazer um acompanhamento sistematizado da evolução dos preços do varejo online brasileiro. É a principal referência como fonte de informações sobre o setor, tanto para as empresas, como para agentes do mercado e consumidores (MCC-ENET, 2020). caracterizando o verdadeiro "show do eu", como enfatiza Paula Sibilia (2016).

Assim, no Instagram, grandes perfis de moda construíram uma narrativa da pandemia Covid-19, ditando uma espécie de "estilo de vida" a ser seguido durante esse período, utilizando de estratégias discursivas para alavancar o consumo de "novos" produtos de moda.

Neste artigo, interessa analisar como perfis de moda, através de discursos de moda interligados à pandemia Covid-19, circulantes no perfil @voguebrasil no Instagram utilizam de mudanças nas ordens dos discursos, como a comodificação, provocando no público seguidor de seu perfil o desejo ao consumo.

O problema de pesquisa visa analisar de que forma os discursos da moda relacionados à pandemia Covid-19 incitam ao consumo, a partir de uma análise de um perfil especializado em moda no Instagram. Analisaremos três postagens publicadas no Instagram pelo perfil @voguebrasil no ano de 2020, período referente ao início da pandemia Covid-19 no Brasil. Nas publicações selecionadas para análise é perceptível excitação ao consumo de moda mesmo em um período pandêmico, e até às diferenças sociais, porque o que retrata nas imagens é um 'isolamento social' acessível apenas para as pessoas que possuem maior poder aquisitivo.

O discurso, e aqui consideramos o universo discursivo que atravessa o campo da moda, não é apenas uma prática de representação, mas também de significação, constituindo e construindo o mundo em significado. Quanto a esta dimensão construtiva do discurso, Fairclough (2001) ressalta que o discurso contribui para a construção das identidades sociais, para a construção das relações interpessoais e para a construção de sistemas de conhecimento e crença. Como metodologia para compreensão da pesquisa, utilizamos o mo- 
delo transdisciplinar (FAIRCLOUGH, 2001), cujo objetivo é investigar o discurso formulado, a partir de uma abordagem da linguagem em uso, a partir da afirmação de que a Análise de Discurso Crítica - ADC é um processo social que se constitui como parte de nossa sociedade.

Portanto, o texto aqui é visto como produto e não como processo; é produto do processo de produção social (FAIRCLOUGH, 2001, p. 24). A análise dos processos de produção e interpretação dos textos, e da análise social dos eventos discursivos.

No campo da prática discursiva, Fairclough (2001) sugere o estudo dos processos de produção, distribuição e consumo textual, isto é, de que forma os textos são produzidos e como eles são distribuídos e consumidos em contextos sociais específicos. Por último, o discurso como prática social deve ser discutido, de acordo com o autor, pelo viés das categorias "ideologia" e "hegemonia", de forma a possibilitar a compreensão de que significações e/ou construções da realidade são identificáveis no discurso, e até que ponto tais construções de sentido contribuem para processos de manutenção do status quo social ou para a transformação da sociedade.

Dessa forma, a análise de discurso proposta pelo autor inclui categorias que viabilizam o entendimento do (s) objetos de estudo e do próprio discurso acerca dos mesmos não só dentro do âmbito textual, mas também enquanto prática social, ou seja, categorias que especificam como o discurso aparece em relação a estruturas e relações sociais e que efeitos ele traz, em termos de reprodução ou transformação das mesmas (FAIRCLOUGH, 2001, p. 289-290).

Neste sentido abordaremos uma análise de três posts publicados no ano de 2020 no perfil @voguebrasil do Instagram, através do método de Análise de Discurso Crítica ( $A D C$ ) na proposta de Fairclough (2001).

\section{CONSUMO, MODA E MÍDIA}

Lipovetsky (2005) cita que a moda não pode ser considerada como um fenômeno universal ou pertencente a todas as épocas. Entende, ainda, que o vestuário tem relação privilegiada com a moda por ser bastante representativo da temporalidade desta e de seus processos. Até os séculos XIX e XX, foi o vestuário quem melhor representou as características do processo de moda.

Somente a partir do fim da Idade Média se reconhece a moda como um sistema, com ordem própria. A partir de então, a renovação das formas se torna um valor mundano e podemos considerar a moda como um elemento importante na sociedade ocidental moderna. A revisão histórica do autor se divide em quatro momentos: moda aristocrática, moda de cem anos, moda aberta e moda consumada.

O estágio aristocrático, que foi considerado o primeiro momento da moda, se deu entre os séculos XIV e XIX, onde já apareciam os traços sociais e estéticos mais característicos da moda, restritos a grupos que monopolizavam o poder de criação e iniciativa. A moda, no sentido moderno do termo, só se instalou ao longo da segunda metade do século XIX, com um sistema de difusão e produção desconhecido até então e que se manteve com regularidade durante um século, no que Lipovetsky (2005) denominou moda de cem anos.

Da metade do século XIX até a década de 60, momento, com efeito, em que o sistema começa a dividir-se e a readaptar-se parcialmente, "a moda vai repousar sobre uma organização a tal ponto estável que é legítimo falar de uma moda de cem anos, primeira fase da história da moda moderna, seu momento heróico e sublime" (LIPOVETSKY, 2005, p. 69). A moda de cem anos não só aproximou as maneiras de vestir, mas também alastrou em todas as classes 
o gosto pelo novo, fazendo das futilidades uma ambição de massa, criando o desejo de moda. A moda de cem anos consagrou os criadores de moda, e deu início a um processo de psicologização da moda, com modelos que concretizam traços de personalidade, caráter e emoções (LIPOVETSKY, 2005).

Segundo Lipovetsky (2005), não somente as roupas podem, então, proporcionar características de estados de espírito, como isso é inseparável de um caráter de individualismo da moda moderna, que tende a cada vez mais apresentar-se como significado de um estado de expressão de personalidade e psicológico. Por volta dos anos 1950, a moda moderna entrou em uma nova fase, denominada de moda aberta, que prolongava e generalizava alguns aspectos trazidos pela moda dos cem anos, como "uma produção burocrática orquestrada por criadores profissionais, uma lógica industrial serial, coleções sazonais e desfiles de manequins com fim publicitário" (LIPOVETSKY, 2005, p. 107).

A diversidade e novidade de estilos surgem juntamente com os valores hedonistas de uma cultura que exaltava a juventude, com maior poder de compra, e a expressão da individualidade. O princípio de imitação social não se referia mais à classe, e sim ao modelo jovem. A questão da marca também se tornou importante como forma de personalizar essa moda produzida em massa. A marca também serve para a identificação com os consumidores e exibição publicitária, em um momento em que a moda se torna cada vez mais heterogênea, fragmentada e plural.

O último momento da moda, conforme Lipovetsky (2005) é o atual (a partir dos anos 1990), que o autor chama de moda consumada, onde se deu a explosão da moda. É um momento em que tudo acaba sendo, de alguma forma, comandado pela moda, ao con- siderarmos a efemeridade como um princípio universal, que se relaciona a objetos, cultura e discursos de sentido. A moda não é mais um privilégio e se estende a todas as classes e instâncias da vida coletiva. Tal momento da moda está diretamente atrelado à sociedade de consumo e reordena a produção e o consumo de massa sob a lei da obsolescência, da sedução e da diversificação (LIPOVETSKY, 2005).

De acordo com o autor:

Pode-se caracterizar empiricamente a "sociedade de consumo" por diferentes traços: elevação do nível de vida, abundância das mercadorias e dos serviços, culto dos objetos e dos lazeres, moral hedonista e materialista, etc. Mas, estruturalmente, é a generalização do processo de moda que a define propriamente. (ibid., p. 159).

Interessa-nos aqui, abordar o momento em que o autor denomina de moda consumada, nesse estágio a moda adota um papel não mais de segregação social, mas sim de prosseguir com a conquista da autonomia individual, uma vez que cada vez mais, em meio a tantas imagens e signos que o consumidor tem à sua escolha, o gosto é cada vez mais importante e individual. Neste contexto, a mídia se insere cada vez mais como elemento fundamental desse sistema, buscando novas formas de influenciar esse consumo.

Acerca da mídia, Lipovetsky (2005) diz que a mídia criou uma nova relação dos indivíduos com o saber, onde através da imprensa e da televisão os indivíduos estão mais a par "daquilo que se passa no mundo", afirmando que grande parte do que sabemos vem da mídia, não se limitando apenas no que se diz respeito aos últimos conhecimentos científicos e técnicos, mas também no que se refe- 
re a vida cotidiana pratica. "O que nos orienta depende cada vez menos de saberes tradicionais e cada vez mais de elementos captados aqui e ali na mídia" (LIPOVETSKY, 2005, p. 228).

Para o autor, a mídia permitiu generalizar a esfera do debate público, alargando o espaço de questionamentos, onde meios midiáticos desencadeiam uma dinâmica de interrogação sobre todas as questões da vida coletiva e individual.

Neste contexto, através de uma abordagem histórica da moda, pode-se observar que desde o surgimento da mídia, ela sempre teve e têm papel fundamental na disseminação e no consumo de moda. Seja programas de TV, rádio, revistas, jornais, filmes, e atualmente as redes sociais, através do imaginário a mídia e a moda constroem na sociedade a sedução e o desejo ao consumo.

Segundo Fairclough (2001), existem tendências abrangentes de mudanças discursivas, como a comodificação, em que o discurso é associado a produção e venda de mercadorias, com isso o discurso se torna uma estratégia para venda de produtos.

Comodificação refere-se ao fenômeno contemporâneo em que muitos bens, serviços, ideias e também pessoas - outrora considerados não comerciais - passam a ser transformados em mercadorias vendáveis. Na comodificação, "tudo passa a ter um preço", representando a centralidade que o consumo - em detrimento da produção ocupa na vida cotidiana. (BECK; CUNHA, 2017 p. 137).

Como mencionado anteriormente, esta proposta situa sua abordagem em um contexto amplo de relações sociais e busca articular aspectos da análise textual.

\section{VOGUE BRASIL NO INSTAGRAM}

Na publicação consta um fundo preto com uma representação de folhas ao redor de uma caixa preta de produtos de cosméticos de beleza. Caixa tem escrito; cuidar, amar, desejar. A publicação segue com a seguinte legenda: Um dos melhores programas para esse momento de distanciamento social é, sem dúvida, investir em rituais de autocuidado (Figura 1). E os Kits da @santapeleoficial criados em parceria com nossa plataforma de bem-estar @voguewellnessbr são ótimos para isso. Com óleos essenciais, banho de ervas e velas aromáticas, entre outras opções, eles fazem com que você se sinta num verdadeiro spa at home. Acesse santapele.com.br para saber mais e escolha o seu \#Vogueapresenta.

Figura 1- Postagem do perfil @voguebrasil, no dia 14 de abril de 2020

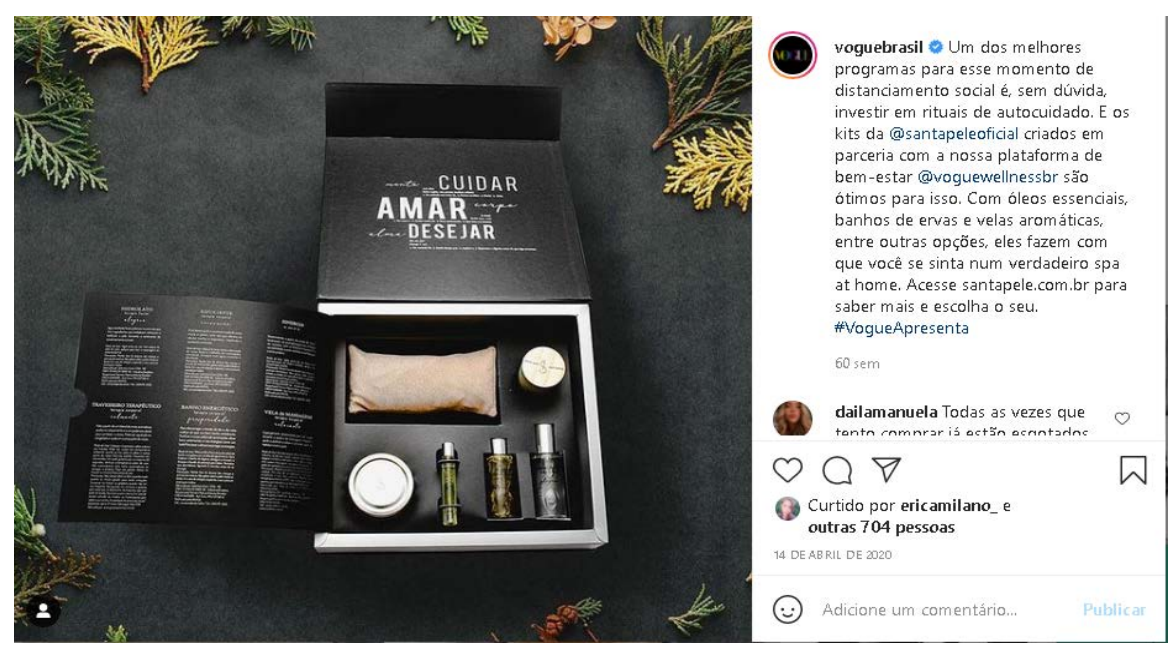

Fonte: Vogue (2020)

\subsection{SOBRE A REVISTA VOGUE - DESCRIÇÃO 01}

A revista Vogue foi fundada há 125 anos nos Estados Unidos da América (EUA). Toda sua história começou em 1892, em Nova York, quando dois jornalistas lançaram um folheto informativo com 
cerca de 30 páginas, onde mostrava mulheres nova-iorquinas de estilo e bem vestidas. No Brasil, a revista chega em $1975^{2}$ pela Editora Três, depois passou a ser propriedade da editora Carta Editorial e posteriormente, em 2010, tornou-se propriedade da Joint Venture Globo Condé Nest. Mais que moda, a revista Vogue reflete marcas do seu tempo, apresentando o lifestyle brasileiro, traduzindo em uma imagem o que há de melhor em conteúdo de moda. Com o surgimento das redes sociais, as revistas de moda tiveram que se adaptar e começar a criar conteúdo para essas mídias, e com a Vogue não foi diferente. A Vogue posta conteúdo na rede social desde o início com muito conteúdo de moda e publicidade.

\subsubsection{Análise}

Na postagem feita pela @voguebrasil é possível observar a incitação ao consumo de produtos cosméticos Skincare. Utilizando do discurso de isolamento social, como um momento de cuidados com a pele como um autocuidado. Criando uma narrativa de isolamento social, como se todas as pessoas pudessem "aproveitar" desse "momento", para cuidar de si. "Produtor(a), produto e consumidor(a) são reunidos como coparticipantes em um estilo de vida, uma comunidade de consumo que a publicidade constrói e simula" (FAIRCLOUGH, 2001, p. 259).

Segundo a Associação Brasileira da Indústria e da Higiene Pessoal, Perfumaria e Cosméticos (ABIHPEC) ${ }^{3}$, uma movimentação a favor do Skincare fez crescer o consumo de produtos faciais, o mercado do setor teve crescimento de $1,1 \%$ no ano passado, acontecendo assim um aumento de $92,8 \%$ no volume de vendas de máscaras faciais

$$
\begin{array}{ll}
\hline 2 & \text { BOZINOSKI (2019). } \\
3 & \text { ABIHPEC (2020). }
\end{array}
$$

de janeiro a maio de 2020, em comparação com o mesmo período em 2019 (VILELA, 2021).

\subsection{DESCRIÇÃO 02}

Na publicação consta um fundo azul escuro, uma modelo está sentada em uma cadeira azul claro modelo de escritório. A modelo está vestida com uma roupa social, calça e blazer de alfaiataria, estampa xadrez em tons sóbrios, usa um cinto largo marrom com fivela grande dourada, da grife italiana Valentino, a modelo também está usando uma meia e um tamanco pantufa, ambos na cor branca, acessórios dourados, brinco e colar (Figura 2).

Figura 2-Postagem do perfil @voguebrasil, no dia 24 de março de 2020

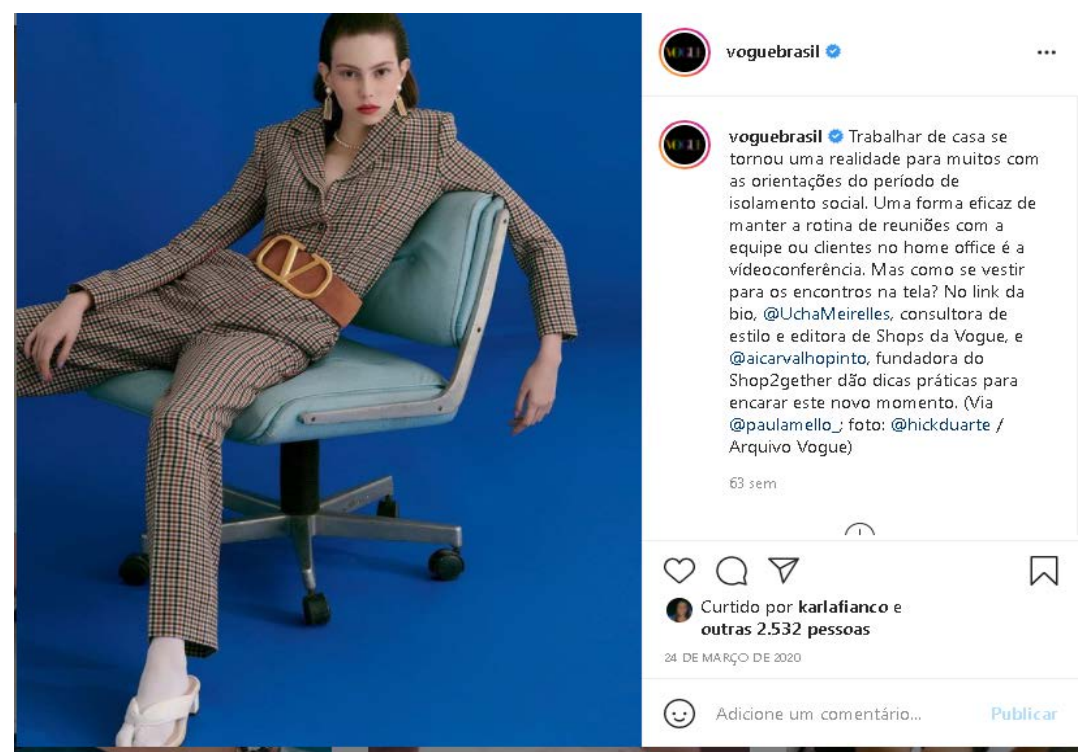

Fonte: Vogue (2020)

A publicação segue com a legenda: "Trabalhar de casa se tornou uma realidade para muitos com as orientações do período de 
isolamento social. Uma forma eficaz de manter a rotina de reuniões com a equipe ou cliente no home office é a videoconferência. Mas como se vestir para tais encontros na tela? No link da bio, @UchaMeirelles, consultora de estilo e editora de Shops da Vogue, @aicarvalhopinto, fundadora do Shop2gether dão dicas práticas para este novo momento" (PAULA MELO, 2021).

\subsubsection{Análise}

Através da imagem que segue com a legenda, é possível analisar na publicação da @voguebrasil a incitação ao consumo de produtos do vestuário, que constrói a narrativa de uma mulher, representando estar em casa, pois está de meias e pantufas, ao mesmo tempo em que está vestida com roupa e cinto de grife, trabalhando em home office no período de isolamento social. Demonstra o quanto a pandemia Covid-19 escancara as desigualdades sociais, a narrativa de trabalho home office, mulher elegante que está sempre na moda, mesmo trabalhando de casa construída pela @voguebrasil não corresponde à realidade de milhares de brasileiras.

Demonstra dessa forma o discurso de isolamento social sendo utilizado como "engrenagem" de vendas para peças de vestuário. "O que os publicitários obtêm das imagens visuais é sua capacidade de evocar na simulação de estilo de vida, capacidade que é geralmente mais poderosa e imediata que a da língua" (FAIRCLOUGH, 2001, p. 259).

A comodificação atinge aspectos tangíveis e simbólicos do cotidiano. Para além da materialidade e do valor de troca, também as simbologias em torno do objeto consumido são valorizadas, lembrando o valor-signo proposto por Baudrillard (2014). O propósito já não é só produzir bens, mas, sim 'organizar' - em círculos comodificantes - as estruturas de produção, de distribuição e consumo, transformando bens tangíveis (e também ativos intangíveis) em mercadorias alienáveis com elevado valor de troca e valor-signo. (BECK, CUNHA, 2017 p. 139).

Neste sentido podemos compreender que a discurso da @voguebrasil se utiliza da persuasão, criar um imaginário nos seus seguidores de um estilo de vestuário que deve ser utilizado para reuniões em home office durante o período de isolamento social, levando seu público ao consumo desses itens divulgados pela publicação.

\subsection{DESCRIÇÃO 03}

A publicação é um post carrossel que segue uma sequência de quatro fotos, mas aqui descreveremos e analisaremos a primeira foto. Uma mulher está sentada de pernas cruzadas em um sofá, no que parece ser uma sala de visita. Ela está vestida com um pijama, camisa de mangas compridas e calça, estampa animal print, segurando um copo com uma bebida, usa um óculos de grau de armação preta e uma toalha cinza no cabelo (Figura 3).

Na legenda da publicação consta: Quem é você em tempos de distanciamento social? De @elizabethbanks de pijama (mas com um drink na mão pronta para o happy hour solo) a @sabrinasato toda arrumada para trabalhar em home office, passando por @ivetesangalo caprichando nas máscaras faciais, celebridades vêm compartilhando como técnicas para manter a sanidade dentro de casa - com direito até a um look meio business, meio pijama que promete ser tendência para as videoconferências, né, @mindykaling? 
Figura 3- Postagem do perfil @voguebrasil, no dia 17 de março de 2020
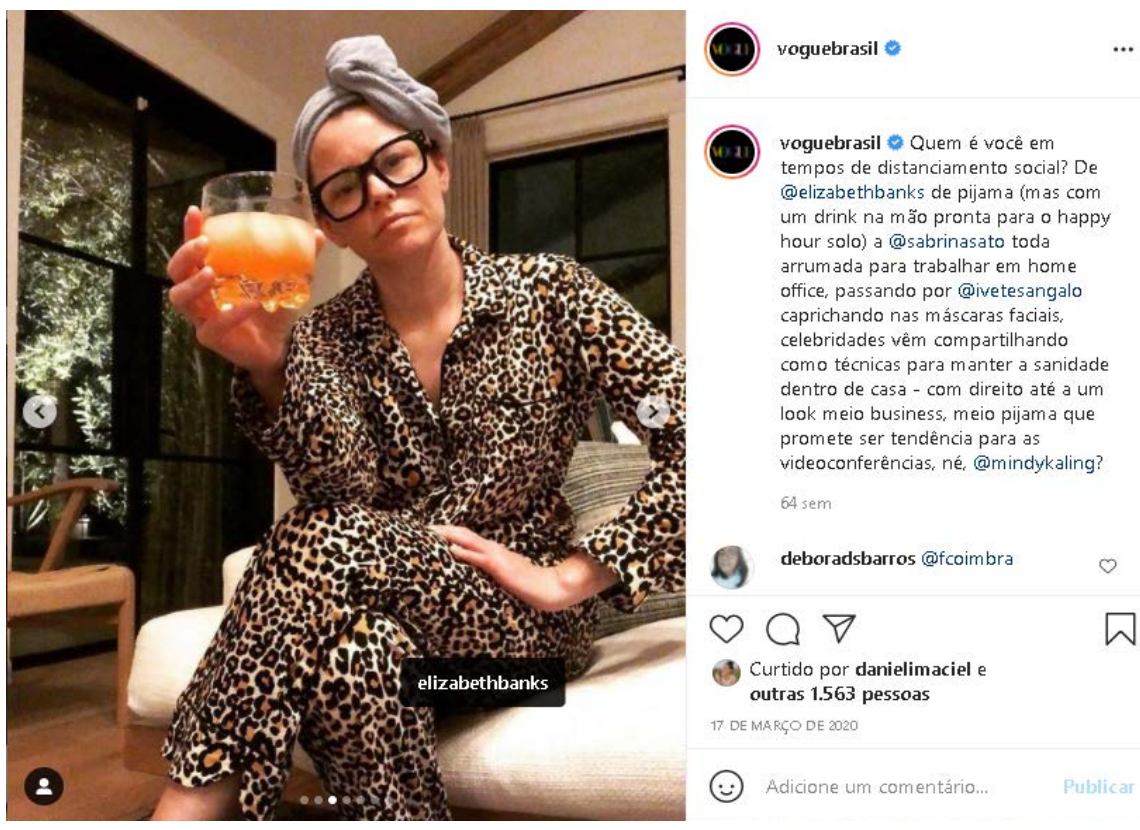

Fonte: Vogue (2020)

\subsubsection{Análise}

A publicação sugere uma narrativa de finais de semana durante $\mathrm{o}$ isolamento social, em que elegantemente uma mulher pode estar com um pijama alinhado e desfrutando de um drink para relaxar em sua luxuosa casa, a legenda do post ainda diz que o pijama promete ser tendência para reuniões por vídeos. $O$ discurso de isolamento social na publicação incita ao consumo de peças para usar em casa, mas sem deixar a "elegância" de fora, com pijamas modelo americano, que também podem ser usados como peças para trabaIhar em home office.

O perfil publica fotos de celebridades, em casas de luxo, roupas de luxo, "aproveitando" o final de semana de um período pandêmico, para tomar drinks e praticar o autocuidado com a pele. $O$ que torna uma narrativa destoante, a realidade de um período pandêmico, em que uma crise sanitária se instala e desencadeia ainda mais, o desemprego no Brasil.

Segundo Campos (2020), o desemprego sobe $27,6 \%$ em quatro meses de pandemia, de acordo com os dados divulgados pela edição mensal da Pesquisa Nacional por Amostra de Domicílios Covid-19 (PNAD Covid-19), a população desocupada no Brasil, que é de 10,1 milhões em maio, passou para 12,3 milhões em julho, e, em agosto, atingiu 12,9 milhões de pessoas, um aumento de $27,6 \%$ desde maio. A taxa de desocupação aumenta em 0,5 ponto percentual de julho para agosto, passando de $13,1 \%$ para $13,6 \%$.

Com isso também, podemos observar que na publicação da @voguebrasil ao mesmo tempo que informa, que está sendo vivenciado pela sociedade um período de isolamento social, ao mesmo tempo ela se utiliza dessa informação como forma de publicidade.

Textos do tipo informação-e-publicidade ou falar-e-vender são comuns em várias ordens de discurso institucionais na sociedade contemporânea. Eles testemunham um movimento colonizador da publicidade do domínio do mercado de bens de consumo, num sentido estrito, para uma variedade de outros domínios. Pode-se relacionar isso com uma tendência atual (associada, na Grã-Bretanha, com a 'cultura empresarial'), no processo de longo prazo de comodificação, de incorporação de novos domínios no mercado, e de ampliação do consumismo. (FAIRCLOUGH, 2001, p. 151).

Fairclough (2001) por meio de técnicas linguístico-discursivas aborda que a publicidade é utilizada com o intuito de canalizar todas as ativi- 
dades para o discurso da venda. Para o autor, a comodificação não deve ser entendida apenas pelo significado de economia, mas sim em sentidos mais gerais, de mudança social e cultural, que interferem nas relações que decorrem destas transações mercantis.

A publicidade é um discurso 'estratégico' por excelência, em termos da distinção feita por Habermas entre linguagem 'estratégica' e 'comunicativa' (1984). É uma questão de construir 'imagens' noutro sentido - modos de apresentar publicamente as pessoas, as organizações e as mercadorias e a construção de identidades ou personalidades para elas. (FAIRCLOUGH, 2001, p. 259).

O que faz desejar não é o objeto, é o nome, o que faz vender não é o sonho, é o sentido (BARTHES, 2009). Assim a moda povoa e constitui o imaginário do nosso tempo, que serão assim cada vez mais atinentes a uma semântica, e a linguista.

\section{CONSIDERAÇÕES FINAIS}

É possível perceber que a tecnologia e as redes sociais, se tornaram ferramentas fundamentais na disseminação e no consumo de produtos de moda durante a pandemia Covid-19. Desde a criação dos meios de comunicação de massa: televisão, rádio, revistas, jornais, somos bombardeados com publicidades que permeiam nosso imaginário. Por meio das redes sociais, especificamente o Instagram, através de texto e imagens a moda constrói uma narrativa de "estilo de vida" a ser seguido, provocando através de seus discursos uma sedução para o consumo. Através dessas narrativas somos seduzidos ao consumo, seduzidos pela "proposta" de estilo de vida que nos é vendido por meio do Instagram, e demais plataformas de redes so- ciais.

Dessa forma o perfil @voguebrasil através do Instagram construiu discursivamente a pandemia Covid-19, com discursos de quarentena, isolamento social, direcionando seu público, para um "estilo de vida" a ser seguido durante esse "período", estrategicamente os conduzindo para o consumo.

Assim, a publicidade utilizou dessas estratégias para alcançar o consumidor no seu isolamento, oferecendo que a pessoa se apresente nas vídeos chamadas da melhor maneira. Ou seja, não é porque alguém está isolado e trabalhando em home office que vai relaxar na aparência. Para isto, as imagens misturam elementos visuais que são de uso caseiro, mas com elegância e na moda. Sem dúvida, são estratégias criativas e oportunas de persuasão e venda.

O mercado tem essa capacidade de usar certas dificuldades inevitáveis para continuar transacionando. Enfatizamos também, que o público da @voguebrasil é elitizado, seleto, com poder aquisitivo, o que torna sua narrativa construída acerca do isolamento social totalmente divergente da realidade da maior parte da população brasileira.

Com o aumento do consumo de produtos de moda em um período pandêmico, e isolamento social, que em tese se ficaria isolado em casa, pode-se constatar que o reflexo disso, seria que mesmo em meio a uma pandemia, o fenômeno da espetacularização do 'EU' nas redes sociais não para de crescer, que mesmo estando isolados queremos ser vistos da melhor forma. A rede social tornou- se a vitrine do 'EU', consome-se para publicar fotos e vídeos nas redes sociais.

Considera-se, por fim que a comodificação gera processos de objetivação, tudo se torna um produto vendável, reforçando a coisificação do próprio sujeito, transformando lugares, gostos e sentimen- 
tos em produtos padronizados, interferindo assim nas esferas de decisões do indivíduo, mesmo nas escolhas mais banais. Assim pode-se levar a crer que a publicidade por meio da persuasão, cria narrativas sedutoras que afetam psicologicamente o imaginário dos sujeitos.

\section{REFERÊNCIAS}

ABIHPEC - Associação Brasileira da Indústria e da Higiene Pessoal, Perfumaria e Cosméticos. Vendas de HPPC crescem 4,7\% em 2020 e totalizam R\$ 122,4 bilhões. 2020. Disponível em: https://abihpec. org.br/vendas-de-hppc-crescem-47-em-2020-e-totalizam-r-1224-biIhoes/. Acesso em: 05 jul. 2021.

BAUDRILLARD, J. A sociedade de consumo. Lisboa, Edições 70, 2014

BECK, C. G.; CUNHA, L. H. H. As múltiplas faces da comodificação e a constituição da crítica acerca das práticas de consumo contemporâneas. Ciências Sociais Unisinos, v. 53, n. 1, p. 136-147, 2017. Disponível em: http://revistas.unisinos.br/index.php/ciencias_sociais/ article/view/csu.2017.53.1.14. Acesso em: 03 jul. 2021.

BLACKMAN, C. 100 anos de moda - a história da indumentária e do estilo do século XX: dos grandes nomes da alta-costura ao prêt-á-porter. São Paulo: Publifolha, 2012.

BOZINOSKI, Mónica. Once upon a time in Vogue. VOGUE Portugal, Lisboa, 22 nov. 2019. Disponível em: https://www.vogue.pt/ vogue-historia-primeiras-vezes\#: :text=A\%20primeira\%20edi\%C3\%A7\%C3\%A30\%20da\%20Vogue\%20na\%20Cond\%C3\%A9\%20 Nast\%20chegou\%20\%C3\%A0s,The\%20Progress\%20of\%20the\%20 Flying. Acesso em: 13 nov. 2021.

CAMPOS, Ana Cristina. o desemprego sobe $27,6 \%$ em quatro meses de pandemia. Agência Brasil, Rio de Janeiro, 23 set. 2020. Disponível em: https://agenciabrasil.ebc.com.br/economia/noticia/2020-09/ desemprego-subiu-276-em-quatro-meses-de-pandemia. Acesso em: 23 jul. 2021.

CAMPOS, C. A. Desemprego subiu 27,6\% em quatro meses de pandemia. Disponível em: https://agenciabrasil.ebc.com.br/economia/ noticia/2020-09/desemprego-subiu-276-em-quatro-meses-de-pandemia. Acesso em: 01 jul. 2021.

ESQUIVEL, L. Pandemia marca o início da revolução no mercado digital de moda. Disponível em: https://jus.com.br/noticias/91102/ pandemia-marca-inicio-da-revolucao-no-mercado-digital-da-moda. Acesso em: 10 jun. 2021.

FAIRCLOUGH, N. Discurso e mudança social. Brasília: UnB, 2001.

LIPOVETSKY, G. O império do efêmero: a moda e seu destino nas sociedades modernas. São Paulo: Companhia das Letras, 2005.

\section{MCC-ENET. Referência em métricas e indicadores do consumo on-} line no Brasil. 2021. Disponível em: https://www.mccenet.com.br/. Acesso em: 10 jun. 2021.

PAULA MELO. Fashion at @voguebrasil. [s.I.], [s.d.], 2021. Instagram: @paulamello_. Disponível em: https://www.instagram.com/ paulamello_Acesso em: 20 jan. 2021.

PORTAL DA COMUNICAÇÃO. Instagram amplia liderança sobre $\mathbf{F a}$ cebook na pandemia. 2021. Negócios da Comunicação. Disponível em: https://portaldacomunicacao.com.br/2020/05/instagram-amplia-lideranca-sobre-facebook-na-pandemia/. Acesso em: 20 jun. 2021.

SIBILIA, Paula. O show do eu: a intimidade como espetáculo. Rio de Janeiro: Editora Contraponto, 2016. E-book. 
VILELA, Luiza. Skin care: um mercado em ascensão na pandemia. Consumidor Moderno, [s.l.], 13 abr. 2021. Disponível em: https:// www.consumidormoderno.com.br/2021/04/13/skin-care-mercado-pandemia/. Acesso em: 30 jun. 2021.

\section{Autoria}

Fabrícia Karla de Oliveira Santos Pereira Mestranda em Comunicação pela Universidade Federal do Piauí. E-Mail: fabriciakarlaa@gmail.com. ORCID: 0000-0003-1725-9513.

\section{Anna Karollina Oliveira Silva}

Mestranda em Comunicação pela Universidade Federal do Piauí. E-Mail: jornalistakarollina@gmail.com. ORCID: 0000-0001-61044873.

\section{Lívia Fernanda Nery da Silva}

Doutora em Ciências da Comunicação pela Universidade do Vale do Rio dos Sinos - UNISINOS. E-mail: livianery02@gmail.com. ORCID: 0000-0003-1837-1304. 